\title{
HIGHER EDUCATION FOR CITIZENS OF CARING DEMOCRACIES
}

\section{J. C. Tronto}

Department of Political Science

University of Minnesota

United States

e-mail: jctronto@umn.edu

\section{ABSTRACT}

Educational development has gained legitimacy as a field of inquiry. Larger structural questions about the place of universities within democracies, however, should be a basic concern of educational developers. This article poses the question, "which side are you on?" It argues that developers can either acquiesce to the conditions of universities in a neoliberal setting or can resist by thinking about universities as a critical tool in the development of caring democracies.

Keywords: educational development, neoliberalism, caring democracy, ethic of care, GI Bill of Rights

\section{“WHICH SIDE ARE YOU ON, WHICH SIDE ARE YOU ON?” (Reece 1931)}

Educational development has had to struggle to gain legitimacy as a field of inquiry. ${ }^{1}$ Part of this struggle, no doubt, has to do with its origins as oppositional to the then prevailing values of universities. As Sue Clegg wrote

"Academic development emerged in the 1960s and 1970s, at the point where universities were set to expand, and many developers subjectively positioned themselves as being on the side of students and against a retrogressive status quo." (Clegg 2009a, 403).

Of course, another part of this disdain quickly became gendered, not only were developers more likely to be women, but universities had been marked primarily as a masculine domain. Clegg quotes Barbara Falk:

"Barbara Falk (2008), one of the earliest pioneers, remembers how in the process of gaining acceptance staff would joke: 'have you been done-over by that little woman yet?' (26). The joke works because of the ways the object of teaching could become associated with the 'little woman' whose practices did not threaten the prestige of disciplines or the prevailing male dominance of the academy." (Clegg, 2009b, 54).

This gendered dimension of educational development may have another dimension as well; because it is associated with care. Perhaps, in the context of higher education, educational development is a practice of developmental care for the students. For such thinkers as Sara Ruddick who coined the term "maternal thinking” (Ruddick 1995), as well as Daniel Engster, 
such developmental issues are central to care; here is Engster's definition:

"everything we do directly to help individuals to meet their vital biological needs, develop or maintain their basic capabilities, and avoid or alleviate unnecessary or unwanted pain and suffering, so that they can survive, develop, and function in society." (Engster 2007, 29; emphasis deleted).

Fisher and Tronto emphasize more the need to "maintain, continue and repair our world so that we may live in it as well as possible" (Fisher and Tronto 1990, 40), but caring and raising children to become adult members of a community surely always constitute a key component of such continuation in any society. If care is a key, the development of children is as well.

But what does developmental care require, and how does naming educational development as a care discourse help us to understand its place in higher education? I would argue, as Engster's definition implies, that "development" always remains relevant to its subject, in this case, to students. Yet a looming problem remains. As Uma Narayan observed, "care" was a discourse used in the UK to justify colonialism in India, helping those others to become Christian and "civilized" was a kind of developmental care (Narayan 1995). This naturally raises the question, on whose side is educational development today? This essay is an attempt to persuade those in educational development that it is not enough for them to go along with the institutionally set requirements for what we now call "student success." The "sides" of the struggle can no longer be defined in terms of being pro-student or not. If higher education institutions themselves do not commit themselves to democratic practices, then the care given to students will only prepare them to live in a world not of their own making. It will, to use Clegg's term about what the original struggle was about, serve to reproduce a highly unequal and "retrogressive status quo."

These are challenging times for democracy; a recent overview by political scientists suggests that support for democracy as a form of government is waning even among so-called established, or consolidated, democracies (Foa and Mounk 2017). These are also challenging times for higher education within democracies. If higher educational institutions (HEIs) are only marked by their historic locus for educating society's elites (and, as Marx long ago observed, provide a central material base for the ideology of the ruling class), then democrats might well have little interest in them. Yet commitments to make universities more democratic are especially strong in the "global South," (cf. Clegg 2009b) both among scholars (eg. Nkoane, Francis and Mahlomaholo 2014; Mahlomaholo 2014; Davids 2014; Swartz et al. 2009) and among students, whose ongoing protests in South Africa began with a demand that "fees must fall" but has now expanded to include the need for a decolonized curriculum. How to achieve these goals is not automatic or easy; a commitment to democracy in higher education is a 
complex and radical idea.

Thinking about the global condition of "educational development" requires that we address questions of power and responsibility, relationality and interdependence, privilege and unfair burdens, on many levels: inside educational institutions, and inside and outside of the many places where such institutions are located, on the local, national, and supranational levels. There are complex issues here, but this article is more concerned with the stark challenge at the heart of these questions: will democracy serve the needs of the people or will it become a term used by an oligarchic set of rulers to placate and silence the many?

As professionals within HEIs, perhaps this level of analysis seems above the pay grade of developers, who are often marginalized in their own institutions (Little and Green 2012). On the one hand, such deep disagreements might seem irrelevant to the role of experts in educational development. We can tell ourselves that getting the students in the door is someone else's problem, when the students are ready to learn, our work guarantees that the skills to allow them to learn better will be there. On the other hand, as professionals, what does it mean if we refuse to look beyond our own narrow, professional tasks, and refuse to take any responsibility for the institution's standing and condition in society? On the one hand, people within higher education are at the mercy of government regulators, funders, and others. On the other hand though, HEIs do retain some freedom to devise their own futures. ${ }^{2}$

One important lesson to learn from care ethics is that a major source of injustice in the world comes from the capability of the relatively privileged to refuse to accept unpleasant or burdensome responsibilities (privileged irresponsibility). The wonderful work done by educational developers deserves much praise. And yet here I want to argue that educational developers do have special responsibilities to think more broadly about the nature of higher education and its place in a democratic society. If one is truly committed to living in a more democratic society, then the question of "which side are you on" becomes the central question.

Many of us (including myself) became involved in higher education because we felt its transformative power upon ourselves and we wanted to pass this gift on to others. In the cultural revolutions of the 1960s, universities were criticized for failing to be "relevant" and for being an "ivory tower" separate from the rest of the world. The riveting vision of Freire's Pedagogy of the Oppressed suggested ways in which education could become liberatory, rather than simply reproducing the existing orders of domination. Now, universities are measured by many features that have nothing to do with the effect of learning on the development of students' intellectual, moral, political, and academic abilities. Instead, universities are held "accountable" to metrics of scholarly "output," "student success" or "customer satisfaction" conceived narrowly, and of "engagement." Rather than being an ivory tower any longer, universities are 
now conceived as engines for economic development and incubators of successful new enterprises. Have universities become too deeply enmeshed in the affairs of the world, surrendering their own unique location and powers in the world? Does educational development lead towards transformation or does it nudge HEIs more closely to accepting the world as it is, and towards convincing people to accept their place in an increasingly unjust, if interconnected, world order?

We live in a democratic age. Yet increasingly, profound inequalities of circumstance determine people's life chances when they are born. Higher education, though now more widespread, has never been for everyone, and those who are lucky enough to complete a degree end up with better life chances. The expansion of higher education has thus not changed its divisive effect. Rather than being an engine for greater democracy, then, has higher education simply become another engine for greater inequality? In the USA, not only does having a college degree affect one's economic future (Ornstein 2007; Rugaber 2017). Even family structure now follows the lines of educational achievement (Carbone and Cahn 2014).

This article will proceed by a rethinking of the term "development" as it applies to higher education development, and then to suggest an alternative that grows out of democratic care. An example of a success story will then be introduced to suggest such thoughts are not utopian, but require political will and imagination.

\section{“DEVELOPMENT”}

In the social sciences, the term "development" was used throughout most of the second half of the twentieth century to describe a process by which "less developed" states were expected to follow the path of development of capitalist, northern, "first world" states, as Albert Hirschman put it, "the underdeveloped countries were expected to perform like wind-up toys, and 'lumber through' the various stages of development ..." (Hirschman 1968, 9, quoted in Chabbott 2013, $85)$.

This single-path idea of development is in part made possible by the growth of sets of uniform measures to evaluate the success of "educational development". But where do these measures, and the ideas about what they measure, come from? Are they as singular in their framing as "development" more generally? Note, too, that an assumption that development means "come and be like us" does not require those who have been previously advantaged in their development to make any sacrifices, rather than encouraging newcomers to follow them and to be just like them. ${ }^{3}$

Having now read many histories of "education development," I am surprised by the absence of a genealogical engagement with the question: why call the improvement of teaching 
"development?" One of the first uses of the term in the USA was in a document called Faculty development in a time of retrenchment (1974) (Lewis 1996). Note the "time of retrenchment" was the beginning of the neoliberal critique that the state could not afford more investments in higher education. Education development grew up with the neoliberal values to "do more with less," and by the 1980s, "academic burnout" was already a discussion. So, in fact, neoliberalism is a parent of education development. The challenge then becomes: is that significant, and if so, in what ways?

But the broader notion of development that elided into this field carries equally disturbing baggage with it. Colette Chabbott described the growth of the idea of development this way:

"In the last half of the twentieth century, much of the world embraced two new fundamental human rights: the right to development and the right to education. Since they were first asserted in the Universal Declaration of Human Rights in 1945, transforming these rights from principles into facts has become imperative for most governments. Subsequently, despite radical differences in financial and administrative means, history, culture, and climate, governments the world over have rationalized this imperative into fairly standardized national development goals, development plans, and frameworks for using education to accelerate socioeconomic development and help distribute its benefits equitably." $(2013,20)$

She continued:

"As such, the [1990 World Conference on Education for All] was clearly not a case of national governments taking rational, measured steps to address the specific needs and unique interests of their particular nation-states in the context of their resources. Rather, it was, in large part, the product of the global environment and a world culture that gave rise to the nation-states themselves and to the international organizations that organize events like the WCEFA. This world culture is not a democratic amalgam of many cultures, rather it is a distillation of Western Enlightenment ideas about progress and justice and the unique role that science plays in promoting them." (2013, 21).

Most importantly for Chabbott, the idea of development consists of two pieces: growth, and then equity following growth. What strikes me about this account of the relationship of development and human rights is that "rights" in the form of justice come after development. From the standpoint of responsibilities, then, something quite bizarre happens. On the one hand, responsibilities become undifferentiated, and as Chabbott notes,

"By this point in the middle of the Fourth Development Decade, the discourse suggests all nations in the world are responsible for reducing poverty globally over time and they are also responsible for minimizing both the global and local impacts of environmental degradation and population growth.” $(2013,21)$.

But, Chabbott notes, this undifferentiated and unmanageable list of responsibilities has an opposite effect: 
"This list of responsibilities - built up over time, rational, consistent with the world cultural values described [earlier] - is patently impossible to implement within the limits of resources historically available to many less industrialized countries and international development organizations. As a result, both nation-state and international organizations pick and choose which mandates they will respect, where, and when. There is therefore much loose coupling between, one the one hand, international and national development policies and, on the other hand, what occurs on a daily basis in organizations attempting to implement those policies at the national and local level in less industrialized countries." $(2013,68)$.

I would push the point even a bit further. Once the responsibilities are shaped into a kind of "pick and choose" set of imperatives, then the placing of growth before concerns of justice and equity takes on a different cast. In a sense, thinking about this from a post-colonial situation, the effect is to excuse the former colonizers for any failures on their part to create just institutions. To use Chabbott's example, if France, like all other nations, has a responsibility for educational development everywhere, then it bears no special responsibility for the underdevelopment ${ }^{4}$ that occurred in its own colonies. The apartheid system in South Africa produced a two-tier educational system. Nicholas Spaull argues that such a two-tiered system continues to exist (Spaull 2013). The question, who is responsible for this outcome, and what can be done to bring the situation to justice, cannot be answered by the notion of "development."

Under these conditions, what can be the purpose of educational development? Do educational developers simply buy into the models that increasingly transform universities into another part of the neoliberal economic order? Let us take a look at the larger global setting within which these questions need to be addressed.

By neoliberalism, I refer to the ruling paradigm of liberal ideas that globalized free markets create the most economic benefit for everyone and therefore should direct government policies everywhere. There are some additional elements: that the state should limit its activities primarily to provide security for those who are willing and able to participate in this economy and protect good citizens from "others," that such free markets are a necessary means for democracy to flourish. (Necessary but not sufficient is the argument of Milton Friedman; it is possible to have authoritarian neoliberal states, such as Singapore.) While few people call themselves "neoliberals," this set of ideas are broadly found throughout the world in ruling parties and governments. While there does seem to be emerging some global forces of opposition in "populist" "fundamentalist" electoral coalitions (e.g., in India, in the "Brexit" vote, in Trump's election in the USA), it remains to be seen how much those movements are really going to change the economic regime, and how much they are simply trading on people's hopes that the economic dislocations of globalization will somehow be stopped without any plan for doing so). Other than security, the most important positive role for the state is to attract 
capital. It is thus not separable from the market, but assumes the role of suitor.

From the standpoint of neoliberalism, higher education is another sector of the economy that can best be organized according to its principles. Starting with the premise that what works best for people is for them to each make wise decisions in the market place, here are some ways that neoliberalism situates itself vis-à-vis higher education. First, since each individual has a choice to make, if, in fact, as argued above, people with higher education degrees earn more, are more likely to form stable families, and are more likely then to be happy, people have a choice to invest in themselves, or not. By this logic, the pay-off belongs to the "fittest." In a sense, the Social-Darwinist roots of such a position suggest, since they are the ones most likely to be "investors," it makes sense to support them. Mario Cuomo eloquently described the logic behind this position already in 1984 :

"President Reagan told us from the beginning that he believed in a kind of Social Darwinism, survival of the fittest...[that] we should settle for taking care of the strong, and hope that economic ambition and charity will do the rest. Make the rich richer, and what falls from the table will be enough for the middle class and those who are trying desperately to work their way into the middle class." (quoted in Isenberg 2016, 315).

One sign of the success of globalization in its effect on universities is how universities around the world have been willing to adopt a standard set of global standards for what constitutes a great university. Universities in the USA shape their practices to score more highly on the US News and World Report lists. Universities in the UK use an elaborate ranking system of scholarship and satisfied customers and proudly hang banners about their status around the campuses. But when one looks closely at these global rankings, they reflect other forms of global power quite closely: in the Shanghai 2016 rankings, for example, the US and UK claim all but two of the top twenty slots (Minsky 2016).

Partly driven by such demands for a uniform thing called "excellence," universities have followed neoliberal labor practices, e.g., hiring more and more part-time and casual instructors (Chakrabortty and Weale 2016), and relying upon student satisfaction surveys as a way to measure learning. Chakrabortty and Weale quote many of the casual faculty with whom they spoke, a University of Nottingham faculty member allowed: "The lack of value that I feel towards me is passed on in my feelings towards the students' education." The question is whether educational developers are a part of this system as well. In one way, it seems so, the ratio of faculty to support staff in universities has also changed dramatically. We might well ask the question: how does the narrative that we are now telling fit with this account of the nature of the university? Are developers there to intercede and protect or bolster students from the harmful effects of coming into contact with such faculty members? 
Another part of the neoliberal agenda in higher education affects first generation college students directly. In recent work, psychologists have begun to notice that more privileged students are likely to be better able to display their individuality and individual distinctiveness. Many students who are the first in their families to go to college have instead been taught that such bragging is not a desirable personality trait. Yet overworked instructors are much more likely to reward students who, like themselves, are independent in this way. The end result is to make universities still more hostile to first generation students (Stephens et al. 2012).

There is one further aspect to the state's support for higher education that is important. In order to make itself attractive to capital, the state must present itself as an attractive place for the work force who keep modern capitalist concerns going - sophisticated high-tech frequent flyers with sophisticated, quirky and constantly changing tastes (Hage 2003). Such individuals themselves are likely to be college graduates and to expect to live in a place with other likeminded people. Thus, there is a way in which creating spaces for such people is a collective interest of the state as well.

What is interesting to me about this argument for public support of higher education is that it relies on a different economic claim than simply self-interest. Here, having more college graduates is not an individual benefit, but an "externality". This is an important way, even in the context of neoliberalism, to make arguments for higher education. Indeed, no less an advocate of free markets than Milton Friedman himself saw a benefit in subsidizing elementary schools and liberal arts colleges, but not necessarily the training of veterinarians. The "neighborhood effects" (his term for externalities) of education justified providing people with a broad education (Friedman 1962, 87-89).

\section{EDUCATING DEMOCRATIC CITIZENS}

Let us consider an alternative possibility: that HEIs would align their interests with those of a broader democratic society. What would a caring democracy look like, and what would it require of higher education?

By caring democracy, I do not mean to invoke any existing democratic state. My starting insight is that caring/care is both the political stance most conducive to real democracy and that democracy is the ethos most generative for caring. ${ }^{5}$ Caring Democracy (Tronto 2013; Tronto 2015) starts from the premise that all societies have a way to organize care. As democracies have evolved, the legacy of care as a concern for those without citizenship privileges has not been fully erased and so democracies have not yet made care congruent with democratic life and values. In my book on the subject, I laid out a path to thinking about democracy as more caring that now seems more distant than ever. The steps are described there: first, that we have 
to realign a system of privileges that make it impossible to discuss how some people take on an unfair load of care responsibilities; second, that everyone's voice must be heard in making these adjustments; third, that democracy is better when caring is organized democratically and that caring is better when it is organized democratically; fourth, that once virtuous circles of caringwith exist among citizens who care for their democracies, trust and solidarity emerge. Along the way, I also observed that neoliberal economic thinking, with its reliance on markets and on framing all "responsibility" as personal responsibility, is one of the great roadblocks to the goal of creating a more caring democracy (Tronto 2013).

In such a condition, caring democracy would make a different set of demands on students than that they pursue their own goals of striking it rich. It would require as well that students balance their individual gain with their responsibilities to their fellow citizens to care about their society and improve it.

The more specific steps that educational developers could take to align their own practices with the concerns of a caring democracy are available from several existing analyses of care. On the one hand, this is an enormously complex task. This is not a simple process, it requires a close analysis of institutions and their many participants, including students, faculty, administrators, the larger "public," and communities within which universities are located. A few tools have emerged by now that allow us to think about how more caring practices might emerge. In the first place, with regard to any care practice, I have argued that focusing on the phases of care (see, e.g., Tronto 2013) allows us dig deeply into a given practice and analyze how it meets care needs. In the second place, I have argued that, in the framework of institutions, we can always focus on power, purpose, and pluralism (Tronto 2010). This analysis, in fact, offers us a check-list for thinking about unjust institutions:

(1) "Misfortune (rather than normal life) causes the need for care.

(2) Needs are taken as given within the organization.

(3) Care is considered a commodity, not a process.

(4) Care receivers are excluded from making judgments because they lack expertise

(5) Care is narrowed to care giving (rather than understanding the full process of care)

(6) Care givers see organizational requirements as hindrances to, rather than support for, care.

(7) Care work is distributed along lines of class, caste, gender, race." (Tronto 2010).

On the other hand, though, we are aided in higher education development by being able to state with some precision what our goals are: Improving education requires setting high expectations and providing high levels of support. ${ }^{6}$ Nevertheless, what high expectations are, and what high levels of support require, are contentious issues. They are, however, exactly the contentious issues that people in democratic societies should argue about.

In sum, in the context of a society committed to democratic values, there must also be a 
commitment to democratic caring and to creating a caring democracy. Educational developers could help to achieve these ends if they set their tasks as developers to reach the proper purposes, rather than to serve neoliberal and consumerist goals.

\section{A CASE OF CARING DEMOCRACY: THE "G. I. BILL"}

By now, the forces arrayed against transforming students into citizens of a caring democracy seems a tall order. Not only do universities have to answer to the demands of a neoliberal order to do more with less public funding, but to meet the needs of more students, and to satisfy those students as consumers, at the same time the quality of public education is fixed by the demand not to spend more money there, either. Students themselves have learned the lesson that no one cares. A social work student quoted by Swartz, et. al. had come to this conclusion when asked about making a larger commitment to social justice:

"[Y]our mind is the battlefield, if you don't change it to accept what happened in the past, to prepare for the future, you are going to miss opportunities, because in this world we don't get what we deserve but what we negotiate." (Swartz et al. 2009, 496).

So, the idea of caring democracy may appear utopian. Is there anyway out?

Let me cite a case when a government exercised largesse towards its citizens, and this act ended up having profound and wide-reaching effects. After World War II, the United States created the so-called "G.I. Bill of Rights," which gave several generous benefits to veterans returning back from war. Previously, the economic stress of troops returning from war had created recessions in every war the US had fought, but now, soldiers were guaranteed tuition and fees for all of their expenses to attend either college, university or a vocational training program, and provided living expenses that varied on the size of their families. Additionally, they received subsidized mortgages to buy new houses. Eventually, eight million took advantage of the bill. Not everyone was excited at the outset, the liberal President of the University of Chicago, Robert Hutchins, worried that the Bill would turn campuses into "hobo jungles" (CBS News 2008). On the other hand, Suzanne Mettler has documented the remarkable changes that this Bill effected, producing, in one way, "The Greatest Generation" (Mettler 2005). Mettler argues that

"Through the program's inclusive design, its fair manner of implementation, and its transformative socioeconomic effects, it communicated to beneficiaries that government was for and about people like them, and thus it incorporated them more fully as citizens. Beneficiaries responded by embracing the duties and obligations of active citizenship. Such effects were most pronounced...among particular groups whose inclusion signified the expansion of social opportunity." (Mettler 2005, 137). 
She continued,

"Long-term beneficiaries gained an especially strong sense that government had made a difference in their lives, and they were more likely both to regard its influence as transformative for their circumstances and to feel that it was their responsibility to give something back to American society. They did so, bolstering the vibrancy of democracy in the postwar era." (Mettler 2005, 148).

Could something like the GI Bill of Rights, though, happen now? If we take the current economic realities as controlling, with its emphasis on less government involvement, on requiring individuals to develop their own "resilience," and its emphasis on global economic (and increasingly educational) competition, the answer is no. However, an international movement committed to reorganizing social life remains a global possibility. Educational developers can contribute by this change by setting as their goal the development of students as democratic citizens.

\section{CONCLUSION}

This essay has argued that educational development might want to return to its initial roots of trying to upset a retrogressive status quo. At its best, "growth and equity" developmental care, neoliberalism, only achieves growth and then, somehow, ignores its initial responsibility to also produce equity. Anti-democratic forces, demagoguery and tyranny have grown throughout the globe in this young century. Those who find democracy too difficult or too demanding (or too equalizing) have learned how to placate the people and then to control them into becoming stupid. Democratic forces need to use a care perspective in order to make certain that the needs of all people are being met in a way so that no one feels excluded.

We still need to answer this question: what is the purpose of higher education in a democracy? To what end should we be developing our capacities as teachers and learners? I propose that if we believe in democratic life, then higher education has a critical role to play, not in producing a separate economic or cultural elite, but in producing citizens who are capable of ensuring that democratic values are deeply embodied in the leaders of societies. This requires that citizens care about democracy itself and that leaders ensure that respect exists for all and trust can thrive among all people. That step requires in turn that institutions, including HEIs, operate in a caring manner on a global level to ensure that people are cared for and to foster the value of care.

\section{NOTES}

1. I cannot here do justice to the rich history of educational development. Among the sources I have found especially useful are these: Leibowitz 2016; Manathunga 2011; Clegg 2009a; Clegg 2009b; 
Fletcher and Patrick 1998; Mintz 1997; Lewis 1996; Lee and McWilliam 2008

2. Consider: "higher education is the object of policy directives imposed by governments and funding agencies. However, higher education also actively defines its own identity and culture in response to social trends." (Leibowitz 2016, 156).

3. An important critic of "development" understood this way is Goldstein (2012).

4. On the concept of underdevelopment, see, among others, Marable (2000).

5. Thanks to Mary Dietz for helping me to clarify this point succinctly.

6. An interesting article reporting what we know about how students learn recently appeared in the New York Times as a way to distinguish good and poor charter schools (non-public schools that receive public funding); it stated this principle. Interesting, it never occurred to the reporter to ask, why don't all public schools meet these expectations? (Leonhardt 2016).

\section{REFERENCES}

Carbone, J. and N. Cahn. 2014. Marriage markets: How inequality is remaking the American family. New York: Oxford University Press.

CBS News. 2008. How the GI Bill of Rights changed America. CBS News. http://www.cbsnews.com/ news/how-the-gi-bill-changed-america/ (Accessed 8 November 2016).

Chakrabortty, A. and S. Weale. 2016. Universities accused of "importing Sports Direct model" for lecturers' pay. London: The Guardian. https://www.theguardian.com/uk-news/2016/nov/16/ universities-accused-of-importing-sports-direct-model-for-lecturers-pay (Accessed 16 November 2016).

Chabbott, C. 2013. Constructing education for development: International organizations and education for all: New York: Routledge.

Clegg, S. 2009a. Forms of knowing and academic development practice. Studies in Higher Education 34(4): 403-416.

Clegg, S. 2009b. Histories and institutional change: Understanding academic development practices in the global "north" and "south". International Studies in Sociology of Education 19(1): 53-65.

Davids, N. 2014. Gratitude as an enactment of democratic citizenship education. South African Journal of Higher Education 28(5): 1513-1524.

Engster, D. 2007. The heart of justice: Care ethics and political theory. New York: Oxford.

Fisher, B. and J. C. Tronto. 1990. Toward a feminist theory of caring. In Circles of care, ed. E. K. Abel and M. Nelson. Albany, NY: SUNY Press.

Fletcher, J. J. and S. K. Patrick. 1998. Not just workshops any more: The role of faculty development in reframing academic priorities. The International Journal for Academic Development 3(1): 39-46.

Foa, R. S. and Y. Mounk. 2017. The signs of deconsolidation. Journal of Democracy 28(1): 5-15.

Friedman, M. 1962. Capitalism and freedom. Chicago: University of Chicago Press.

Goldstein, A. 2012. Poverty in common: The politics of community action during the American Century. Durham, NC: Duke University Press.

Hage, G. 2003. Against paranoid nationalism. Annandale, NSW, Pluto Press Australia.

Hirschman, A. O. 1968. Underdevelopment, obstacles to the perception of change, and leadership. Daedalus 97(3): 925-937.

Isenberg, N. 2016. White trash: The 400-year untold history of class in America. New York: Penguin.

Lee, A. and E. McWilliam. 2008. What game are we in? Living with academic development. International Journal for Academic Development 13(1): 67-77.

Leibowitz, B. 2016. The professional development of academics as teachers: Reconsiderations. In Researching higher education: International perspectives on theory, policy and practice, ed. J. M. 
Case and J. Huisman. New York: Routledge.

Leonhardt, D. 2016. Schools that work. New York Times, 4 November 2016.

Lewis, K. G. 1996. Faculty development in the United States: A brief history. The International Journal for Academic Development 1(2): 26-33.

Little, D. and D. A. Green. 2012. Betwixt and between: Academic developers in the margins. International Journal for Academic Development 17(3): 203-215.

Mahlomaholo, S. M. G. 2014. Higher education and democracy: Analysing communicative action in the creation of sustainable learning environments. South African Journal of Higher Education 28(3): 678-696.

Manathunga, C. 2011. The field of educational development: Histories and critical questions. Studies in Continuing Education 33(3): 347-62.

Marable, M. 2000. How capitalism underdeveloped Black America: Problems in race, political economy, and society. London: Pluto Press.

Mettler, S. 2005. Citizens to soldiers: The G.I. Bill and the making of the greatest generation. New York: Oxford University Press.

Minsky, C. 2016. Shanghai ranking: Academic ranking of world universities 2016 results announced. London: Times Higher Education. https://www.timeshighereducation.com/student/news/ shanghai-ranking-academic-ranking-world-universities-2016-results-announced (Accessed 16 November 2016).

Narayan, U. 1995. Colonialism and its others: Considerations on rights and care discourses. Hypatia 10(2): 133-40.

Nkoane, M. M., D. Francis and S. M. G. Mahlomaholo. 2014. Higher education for democratic citizenry through the creation of sustainable learning environments-leading article: Part 1: Exploration of the critical relationship between higher education and the development of democracy in South Africa. South African Journal of Higher Education 28(3): 673-677.

Ornstein, A. C. 2007. Class counts: Education, inequality, and the shrinking middle class. Lanham, MD: Rowman \& Littlefield Pub. Group, Inc.

Reece, F. 1931. Which side are you on?

Ruddick, S. 1995. Maternal thinking: Toward a politics of peace. Rev., Boston: Beacon.

Rugaber, C. 2017. Pay gap between college grads and everyone else at a record. New York Times, 13 January: A1.

Spaull, N. 2013. Poverty and privilege: Primary school inequality in South Africa. International Journal of Educational Development 33(5): 436-447.

Stephens, N. M., S. A. Fryberg, H. R. Markus, C. S. Johnson and R. Covarrubias. 2012. Unseen disadvantage: How American universities' focus on independence undermines the academic performance of first-generation college students. Journal of Personality and Social Psychology 102(6): 1178-1197.

Swartz, L., P. Rohleder, V. Bozalek, R. Carolissen, B. Leibowitz and L. Nicholls. 2009. "Your mind is the battlefield": South African trainee health workers engage with the past. Social Work Education 28(5): 488-501.

Tronto, J. C. 2010. Creating caring institutions: Politics, plurality, and purpose. Ethics and Social Welfare 4(2): 158-171.

Tronto, J. C. 2013. Caring democracy: Markets, equality and justice. New York: NYU Press.

Tronto, J. C. 2015. Who cares? How to reshape a democratic politics. Ithaca NY: Cornell University Press. 